\title{
Efeito antagônico de fungos predadores dos gêneros Monacrosporium, Arthrobotrys e Duddingtonia sobre larvas infectantes de Cooperia sp. e Oesophagostomum sp.
}

\author{
[Antagonistic effect of nematophagous fungi Monacrosporium, Arthrobotrys and Duddingtonia \\ on infective Cooperia sp. and Oesophagostomum sp. larvae]
}

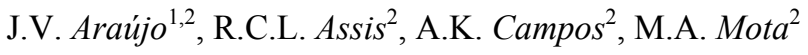 \\ ${ }^{1}$ Departamento de Veterinária - UFV \\ Av. P.H. Rolfs, $\mathrm{s} / \mathrm{n}$ \\ 36570-000 - Viçosa, MG \\ ${ }^{2}$ Bolsista de produtividade em pesquisa do $\mathrm{CNPq}$
}

\begin{abstract}
RESUMO
Seis isolados dos fungos nematófagos Monacrosporium thaumasium (isolado NF 34A), Monacrosporium sinense (isolado SF 470), Monacrosporium appendiculatum (isolado CGI), Arthrobotrys robusta (isolado I 31), Arthrobotrys cladodes (isolado CG 719) e Duddingtonia flagrans (isolado CG 768) foram avaliados em laboratório quanto à capacidade de predar larvas infectantes de Cooperia sp. e Oesophagostomum sp. Nos testes in vitro, os fungos foram eficientes em predar os nematóides $(\mathrm{P}<0,05)$, e não houve variação na capacidade predatória entre os fungos testados $(\mathrm{P}>0,05)$ durante os cinco dias do ensaio. Estruturas reprodutivas (conídios) foram encontradas em todos os isolados no quinto dia. Todos os fungos testados são promissores para serem utilizados no controle biológico de Cooperia sp. e Oesophagostomum sp., parasitos de bovinos.
\end{abstract}

Palavras-chave: controle biológico, Monacrosporium spp., Arthrobotrys spp., Duddingtonia flagrans, Cooperia sp., Oesophagostomum sp.

\begin{abstract}
Six isolates of nematophagous fungi Monacrosporium thaumasium (isolate NF 34A), Monacrosporium sinense (isolate $S F$ 470), Monacrosporium appendiculatum (isolate CGI), Arthrobotrys robusta (isolate I 31), Arthrobotrys cladodes (isolate CG 719) and Duddingtonia flagrans (isolate CG 768) were evaluated under laboratory conditions regarding the capacity to entrap infective Cooperia $\mathrm{sp}$. and Oesophagostomum sp. larvae. In the in vitro tests the fungi tested were equally efficient to prey the nematodes $(P<0.05)$ during the five days of the experiment. Reproductive structures (conidia) from all isolates were visualized in $5^{\text {th }}$ day. All fungal isolates were efficient in the control of bovine Cooperia sp. and Oesophagostomum sp. parasites.
\end{abstract}

Keywords: bilological control, Monacrosporium spp., Arthrobotrys spp., Duddingtonia flagrans, Cooperia sp., Oesophagostomum sp.

Recebido em 25 de maio de 2004

Aceito em 11 de fevereiro de 2006

E-mail: jvictor@ufv.br

Apoio: CNPq e FAPEMIG 


\section{INTRODUÇÃO}

Dentre os fatores que interferem no desenvolvimento da atividade pecuária, as helmintoses gastrintestinais ocupam lugar de destaque (Macrae, 1993). Os prejuízos estão relacionados à baixa produção, aos custos com tratamentos profilático e curativo e, em casos extremos, à morte dos animais. Enquanto nos países desenvolvidos os gastos atribuídos aos custos com controle são significativos, nos países em desenvolvimento, as doenças parasitárias causam prejuízos pela diminuição na produção e na restrição à criação de animais com reduzida susceptibilidade às parasitoses, porém com baixas performances produtivas. As raças de animais com melhores índices produtivos, quase sempre criadas nos países desenvolvidos, raramente se sobressaem em ambientes onde ocorrem parasitos durante todo o ano (Perry e Randolph, 1999).

O conhecimento sobre a epidemiologia dos parasitos e suas interações com os hospedeiros em um determinado ambiente e sistema produtivo é o requerimento mais importante no estabelecimento de um sistema de controle efetivo. A falta dessas informações pode levar à utilização inadequada de tratamentos antihelmínticos, relacionada ao rápido desenvolvimento de resistência e traduzida em aumentos de casos clínicos e de perdas produtivas. Os programas de controle parasitários eficientes baseiam-se em informações sobre presença de larvas no ambiente, detecção de fontes de infecção, conhecimento sobre as exigências climáticas para eclosão de ovos e viabilidade larvar. Medidas preventivas baseadas nessas informações podem diminuir a freqüência de tratamentos químicos e, quando associadas a outras formas de controle, podem reduzir a dependência dos anti-helmínticos (Stromberg, 1997; Barger, 1999; Stromberg e Averbeck, 1999).

Como regra de manutenção dos sistemas biológicos, toda população é regulada por antagonistas. Esse processo ocorre espontaneamente na natureza e não é dependente da interferência do homem. Na ausência de controladores naturais, a população de um determinado organismo poderia aumentar indiscriminadamente. Normalmente, o termo controle biológico aplica-se à utilização de antagonistas naturais disponíveis no ambiente, para diminuir a um limiar subclínico e economicamente aceitável a população de um agente causador de perdas produtivas à atividade pecuária ou agrícola (Grønvold et al., 1996). Na prática, o controle biológico não atua sobre estágios internos de parasitos; contudo, concentra suas ações sobre os hospedeiros intermediários, paratênicos, vetores e estágios larvais de vida livre, diminuindo a fonte de infecção para os hospedeiros finais; além disso, causa menos efeitos negativos no ambiente que os métodos químicos.

Segundo Waller e Larsen (1993), o uso de fungos predadores de nematóides parasitos auxilia o controle químico desses parasitos e deveria ser feito não somente em condições em que ocorrer previsão de maior infestação de pastagens por ovos e larvas de helmintos, mas, também, quando houver melhores condições para o crescimento dos fungos no meio ambiente, prevenindo, assim, o parasitismo clínico e a conseqüente perda de produtividade.

As espécies de fungos Duddingtonia flagrans, Monacrosporium thaumasium, $M$. appendiculatum, M. sinense, Arthrobotrys conoides, $A$. cladodes $e$ A. robusta são identificadas como nematófagas (Barron, 1977) e têm sido estudadas quanto ao seu potencial como agentes controladores biológicos de nematóides gastrintestinais de animais domésticos (Alves et al., 2003; Araújo et al., 1993, 1998, 1999; Dimander et al., 2003; Gomes, 1998; Larsen et al., 1995).

O objetivo deste estudo foi comparar a eficácia de isolados dos fungos predadores de larvas de nematóides dos gêneros Monacrosporium, Arthrobotrys e Duddingtonia, isoladamente e em associações, no controle in vitro de larvas de terceiro estádio de Cooperia sp. e Oesophagostomum sp., parasitos gastrintestinais de bovinos.

\section{MATERIAL E MÉTODOS}

Panagrellus sp. (nematóides de vida livre) foram mantidos em placas de Petri com meio de aveia em flocos, umedecida e amassada. Esses nematóides foram extraídos do meio de cultura 
pela imersão de pequenas quantidades de aveia em água destilada no aparelho de Baermann e coletados em tubos de hemólise após seis horas de decantação.

Seis isolados de fungos predadores de nematóides, sendo três isolados do gênero Monacrosporium: $M$. thaumasium (NF 34A), $M$. appendiculatum (CGI) e $M$. sinense (SF 470); dois isolados do gênero Arthrobotrys; A. robusta (I 31) e A. cladodes (CG 719) e um isolado do gênero Duddingtonia; D. flagrans (CG 768), oriundos da micoteca do Departamento de Veterinária da Universidade Federal de Viçosa, foram mantidos a $4{ }^{\circ} \mathrm{C}$, ao abrigo da luz e em tubos de ensaio contendo corn-meal-agar 2\% (CMA 2\%). Esses isolados brasileiros foram obtidos pelo método do espalhamento do solo de Duddington (1955), modificado por Santos et al. (1991).

As larvas infectantes de Cooperia sp. e Oesophagostomum sp. foram obtidas das fezes de bezerros mestiços Holandês $\times$ Zebu naturalmente infectados, com aproximadamente seis meses de idade, oriundos da região de Viçosa, Minas Gerais. As larvas foram quantificadas e identificadas sob microscópio óptico $(10 \times)$, a proporção foi de 58,0\% de Cooperia sp. e de 42,0\% de Oesophagostomum sp.

Discos de cultura de $4 \mathrm{~mm}$ de diâmetro foram transferidos dos isolados fúngicos mantidos em tubos de ensaio contendo CMA $2 \%$ para placas de Petri de $8,5 \mathrm{~cm}$ de diâmetro, contendo $20 \mathrm{ml}$ de meio CMA $2 \%$ e mantidos em estufa a $25^{\circ} \mathrm{C}$, no escuro e por sete dias. Após o crescimento fúngico, novos discos de cultura foram transferidos para placas de Petri contendo $20 \mathrm{ml}$ de meio ágar-água 2\% (AA $2 \%$ ) onde foram acrescidos de $1 \mathrm{ml}$ de suspensão de água destilada contendo 1000 larvas de Panagrellus sp., diariamente, durante um período de 21 dias para a indução da formação de conídios fúngicos. Quando o completo desenvolvimento fúngico foi observado, $5 \mathrm{ml}$ de água destilada foram adicionados a cada placa de Petri, sendo que conídios e fragmentos miceliais foram removidos conforme descrito por Araújo et al. (1993).

Sessenta e nove grupos de larvas foram formados, em placas de Petri de $8,5 \mathrm{~cm}$ de diâmetro, contendo $20 \mathrm{ml}$ de AA $2 \%$ previamente marcadas em campos de $4 \mathrm{~mm}$ de diâmetro.
Larvas e conídios de fungos foram quantificados com auxílio de câmara de Neubauer. Cada grupo continha 1000 larvas infectantes de nematóides gastrintestinais de bovinos, Cooperia sp. e Oesophagostomum sp., e 1000 conídios de isolados fúngicos. Seis isolados fúngicos foram combinados em todas as associações possíveis, sendo que de cada uma dessas combinações formou-se um grupo. O valor numérico dos conídios foi quantificado de forma que cada placa contivesse 1000 conídios, independente do número de fungos utilizados nas associações. Seis desses grupos continham 1000 conídios de cada isolado fúngico individualmente. Nas combinações de dois fungos, os grupos continham 500 conídios, nas de três 333 conídios, nas de quatro 250 conídios, nas de cinco 200 conídios e na de seis 167 conídios de cada isolado.

Foram formados grupos-controle referentes a cada isolado fúngico ou associação com a mesma proporção de conídios. Da mesma forma, foram formados seis grupos-controle contendo suspensão de 1000 larvas infectantes por placa, sem a adição de qualquer isolado fúngico. Para cada grupo, realizaram-se cinco repetições.

A cada 24 horas, 10 campos de cada placa de Petri dos vários grupos foram examinados em microscópio, com objetiva de $10 \times$, onde foram quantificados os números de larvas infectantes livres por campo de $4 \mathrm{~mm}$ de diâmetro, durante cinco dias. Concomitantemente, observou-se a presença de larvas predadas em armadilhas e o desenvolvimento de conídios. Foram realizadas leituras diárias em cada placa por cinco dias. $\mathrm{O}$ número médio de larvas infectantes foi calculado em cada grupo, e a eficiência de cada isolado e combinação foi avaliada pelo teste Tukey (1 e $5 \%$ de probabilidade).

\section{RESULTADOS E DISCUSSÃO}

O uso dos fungos nematófagos no controle biológico de animais parasitados por helmintos pode reduzir a contaminação das pastagens, agindo diretamente nas larvas presentes no meio ambiente (Araújo et al., 1999, 2000).

As espécies de fungos empregadas e suas associações foram as primeiras a serem utilizadas em um mesmo trabalho para controlar larvas 
infectantes de Cooperia sp. e Oesophagostomum sp.

As Fig. 1 e 2 representam o número médio de larvas infectantes livres de nematóides gastrintestinais de bovinos em placas de Petri com AA 2\%. Após cinco dias, foi comprovada diferença significativa $(\mathrm{P}<0,05)$ entre todos os isolados fúngicos e os grupos-controle. Todos os isolados fúngicos foram eficientes como larvicidas de Cooperia sp. e Oesophagostomum sp. Uma pequena diminuição do número de larvas observada nas placas dos grupos-controle ao longo de cinco dias se deve ao fato de haver migração de parte delas para a periferia das placas, onde se encontra maior umidade.

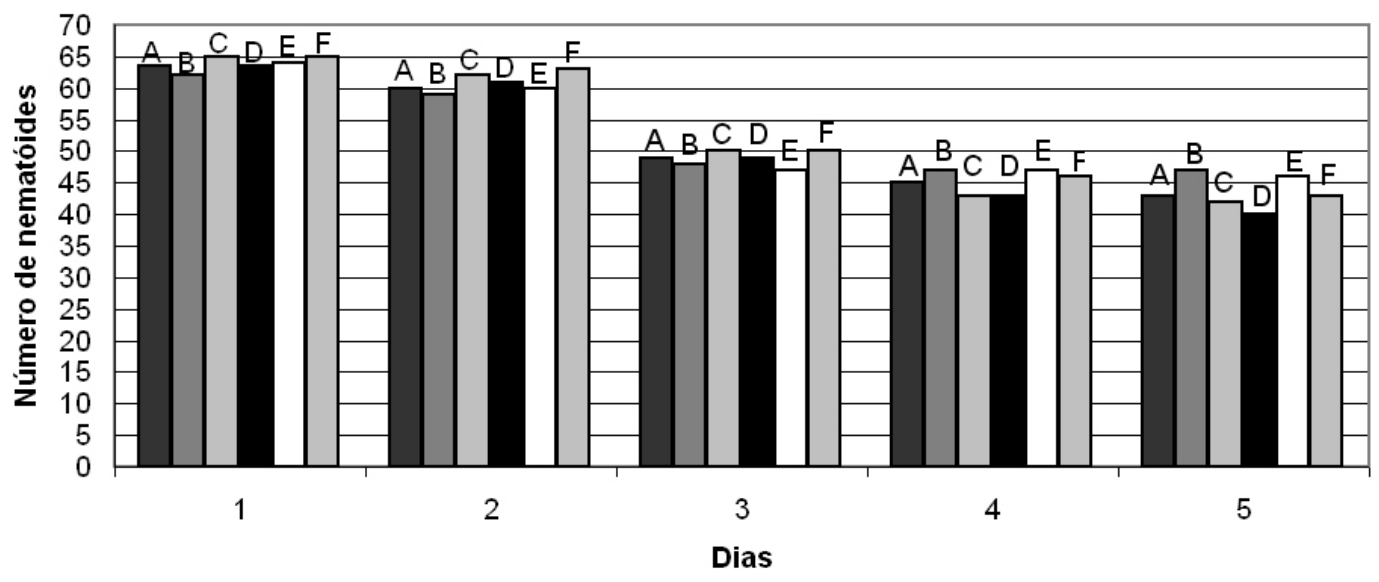

\begin{tabular}{lll|}
\hline A-CONTROLE NF34A & $\square$ B-CONTROLE SF470 & $\square$ C-CONTROLE CGI \\
$\square$ D-CONTROLE I31 & $\square$ E-CONTROLE CG719 & $\square$ F-CONTROLE CG768
\end{tabular}

Figura 1. Número médio de larvas infectantes livres de nematóides parasitos gastrintestinais de bovinos por campo de $4 \mathrm{~mm}$ de diâmetro em placas de Petri com agar-água 2\% para os grupos-controle dos fungos I 31 (Arthrobotrys robusta), CG 719 (Arthrobotrys cladodes), CG 768 (Duddingtonia flagrans), SF 470 (Monacrosporium sinense), CGI (Monacrosporium appendiculatum) e NF 34A (Monacrosporium thaumasium), durante cinco dias.

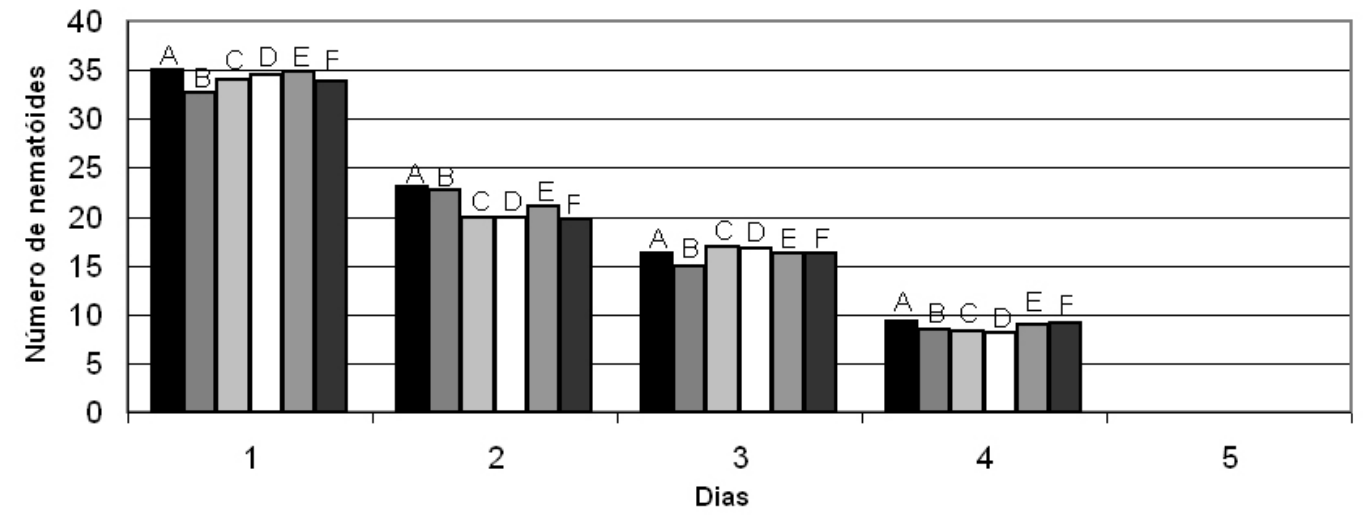

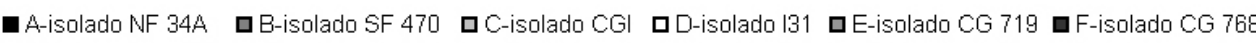

Figura 2. Número médio de larvas infectantes livres de nematóides parasitos gastrintestinais de bovinos por campo de $4 \mathrm{~mm}$ de diâmetro em placas de Petri com agar-água 2\% para os isolados fúngicos I 31 (Arthrobotrys robusta), CG 719 (Arthrobotrys cladodes), CG 768 (Duddingtonia flagrans), SF 470 (Monacrosporium sinense), CGI (Monacrosporium appendiculatum) e NF 34A (Monacrosporium thaumasium), durante cinco dias. 
As Fig. 3, 4, 5, 6 e 7 representam o número médio de larvas infectantes livres de nematóides gastrintestinais de bovinos em placas de Petri com AA $2 \%$ marcadas em campos de $4 \mathrm{~mm}$ de diâmetro durante as cinco leituras de 10 campos aleatórios para as associações fúngicas constituídas de dois, três, quatro, cinco e seis isolados fúngicos utilizados, respectivamente.

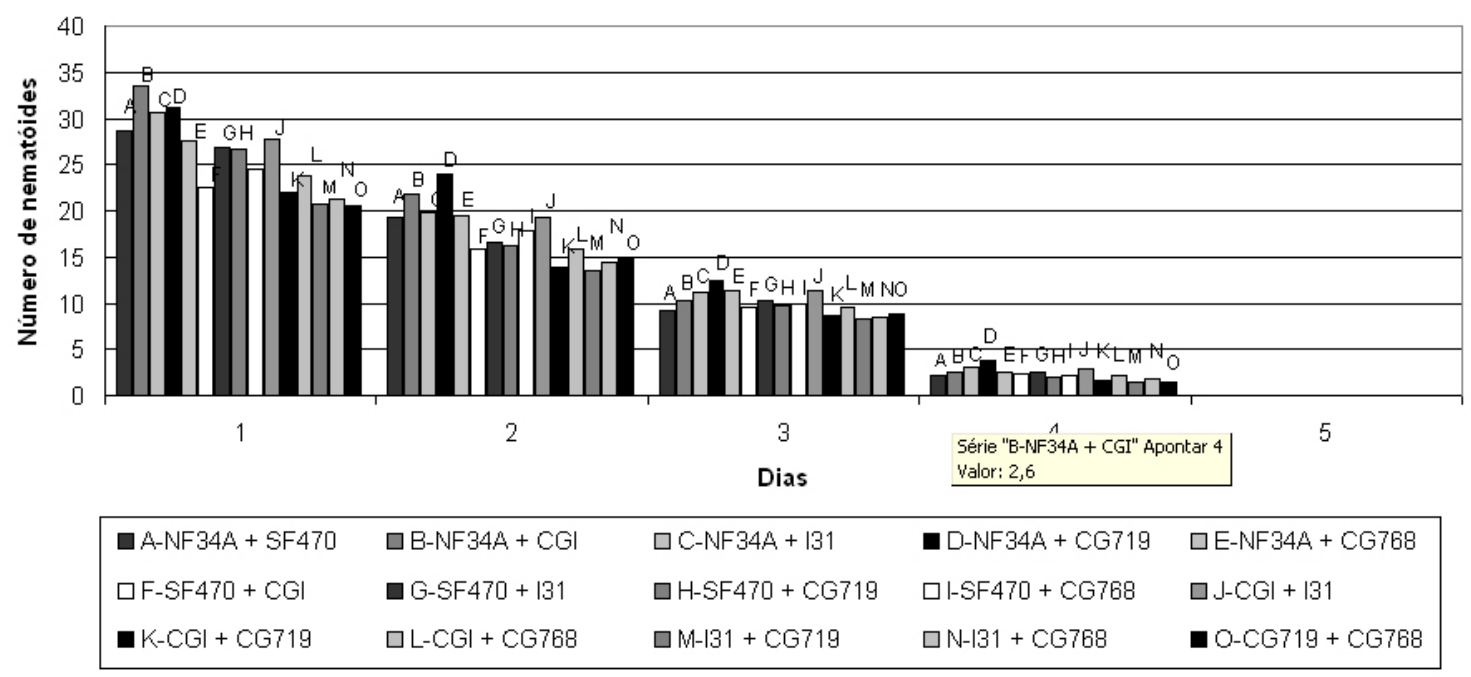

Figura 3. Número médio de larvas infectantes livres de nematóides parasitos gastrintestinais de bovinos por campo de $4 \mathrm{~mm}$ de diâmetro em placas de Petri com agar-água 2\% para as associações fúngicas de dois isolados. I 31 (Arthrobotrys robusta), CG 719 (Arthrobotrys cladodes), CG 768 (Duddingtonia flagrans), SF 470 (Monacrosporium sinense), CGI (Monacrosporium appendiculatum) e NF 34A (Monacrosporium thaumasium), durante cinco dias.

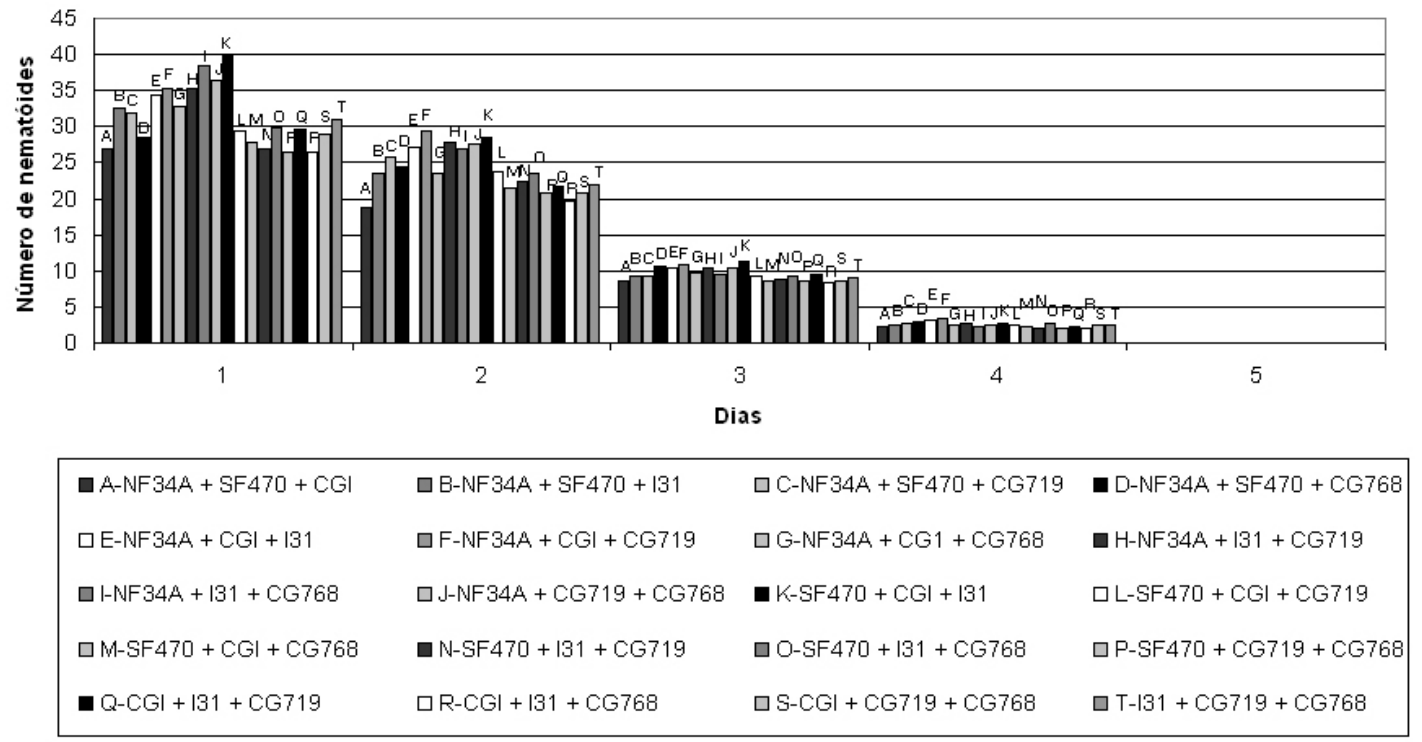

Figura 4. Número médio de larvas infectantes livres de nematóides parasitos gastrintestinais de bovinos por campo de $4 \mathrm{~mm}$ de diâmetro em placas de Petri com agar-água 2\% para as associações fúngicas de três isolados. I 31 (Arthrobotrys robusta), CG 719 (Arthrobotrys cladodes), CG 768 (Duddingtonia flagrans), SF 470 (Monacrosporium sinense), CGI (Monacrosporium appendiculatum) e NF 34A (Monacrosporium thaumasium), durante cinco dias. 


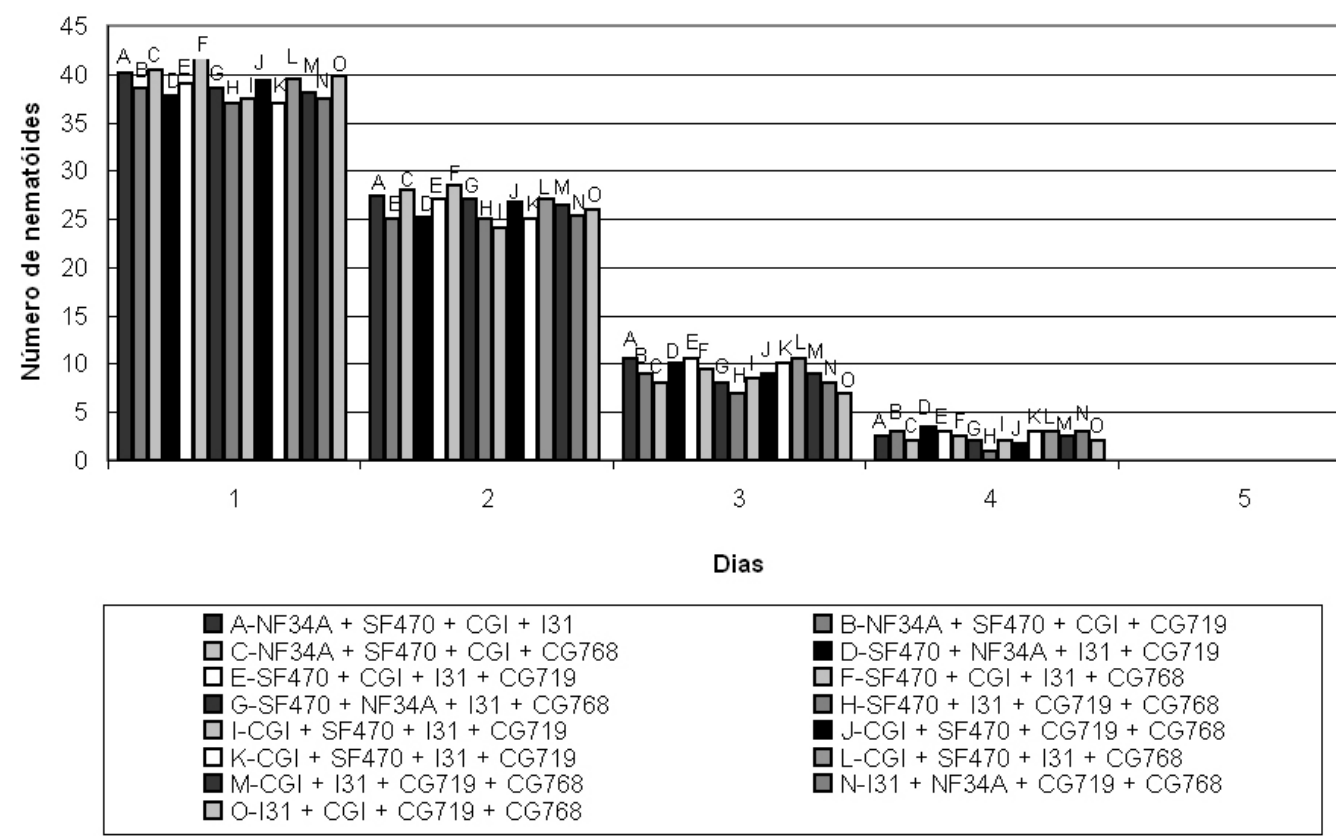

Figura 5. Número médio de larvas infectantes livres de nematóides parasitos gastrintestinais de bovinos por campo de $4 \mathrm{~mm}$ de diâmetro em placas de Petri com agar-água 2\% para as associações fúngicas de quatro isolados. I 31 (Arthrobotrys robusta), CG 719 (Arthrobotrys cladodes), CG 768 (Duddingtonia flagrans), SF 470 (Monacrosporium sinense), CGI (Monacrosporium appendiculatum) e NF 34A (Monacrosporium thaumasium), durante cinco dias.

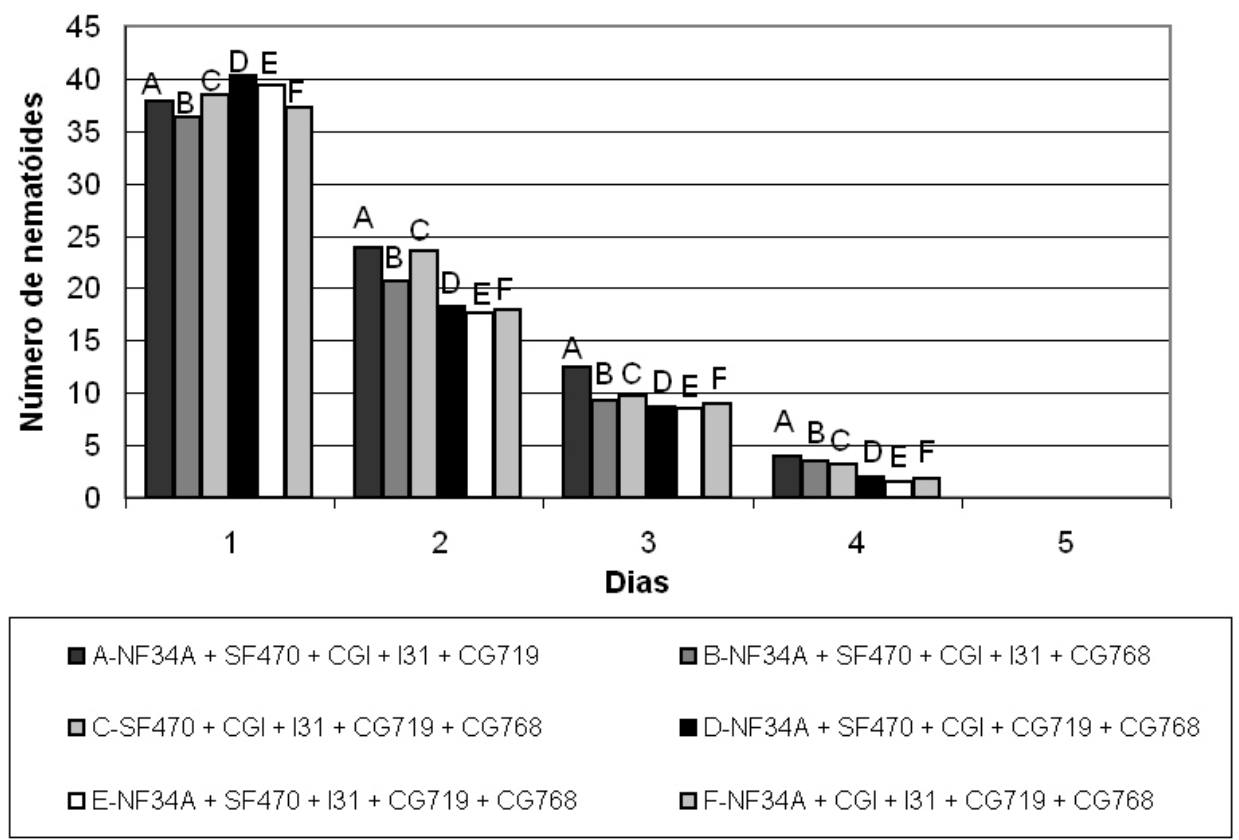

Figura 6. Número médio de larvas infectantes livres de nematóides parasitos gastrintestinais de bovinos por campo de $4 \mathrm{~mm}$ de diâmetro em placas de Petri com agar-água 2\% para as associações fúngicas de cinco isolados. I 31 (Arthrobotrys robusta), CG 719 (Arthrobotrys cladodes), CG 768 (Duddingtonia flagrans), SF 470 (Monacrosporium sinense), CGI (Monacrosporium appendiculatum) e NF 34A (Monacrosporium thaumasium), durante cinco dias. 


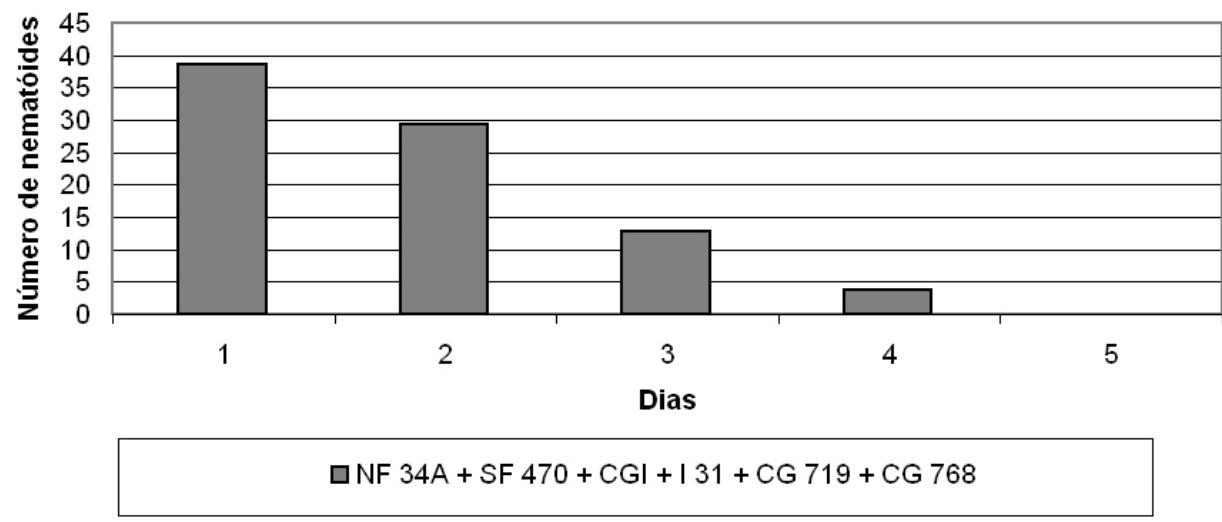

Figura 7. Número médio de larvas infectantes de nematóides parasitos gastrintestinais de bovinos por campo de $4 \mathrm{~mm}$ de diâmetro em placas de Petri com agar-água $2 \%$ para a associação fúngica de seis isolados I 31 (Arthrobotrys robusta), CG 719 (Arthrobotrys cladodes), CG 768 (Duddingtonia flagrans), SF 470 (Monacrosporium sinense), CGI (Monacrosporium appendiculatum) e NF 34A (Monacrosporium thaumasium), durante cinco dias.

Não houve diferença $(\mathrm{P}>0,05)$ entre as associações e os diversos isolados fúngicos usados para predar Cooperia sp. e Oesophagostomum sp. Além disso, não houve variação da proporção inicialmente colocada em cada placa de 58,0\% de Cooperia sp. e de $42,0 \%$ de Oesophagostomum sp., indicando que os fungos não foram seletivos para um determinado gênero de nematóide.

Verifica-se que, nas associações fúngicas, houve menor proporção de larvas infectantes livres do que nos grupos-controle $(\mathrm{P}<0,05)$. Foram observadas presenças de armadilhas em todas as placas com fungos desde a primeira leitura, e na leitura final, todas as placas apresentaram conídios. Resultados semelhantes foram descritos por Waghorn et al. (2002), quando da associação de fungos nematófagos Duddingtonia, Monacrosporium e Harposporium sobre estádios de vida livre de Ostertagia circuncincta.

Em todos os grupos testados, a maior taxa de predação das larvas ocorreu nas primeiras 48 horas da adição do fungo às placas. A diferenciação da hifa e das estruturas de captura ocorreu dentro das 24 horas após o contato fúngico com as larvas, o que está de acordo com o relatado por Pramer (1964).
D. flagrans é a espécie de fungo nematófago mais estudada e foi escolhida por Larsen (1999) como a mais promissora. No entanto, no presente trabalho, D. flagrans não foi mais eficaz no controle in vitro de Cooperia sp. e Oesophagostomum sp. do que os fungos $A$. robusta, A. cladodes, M. appendiculatum, M. sinense e $M$. thaumasium. A escolha de um fungo nematófago deveria levar em consideração não só testes in vitro, mas também testes em campo, onde espécies de fungos da localidade deveriam ser as preferidas para serem utilizadas no controle de nematóides.

Recentemente, formulações à base de alginato de sódio têm sido usadas experimentalmente no controle de nematóides parasitas de animais por alguns laboratórios de pesquisa. Essa formulação tem demonstrado bons resultados em condições de laboratório e em campo (Alves et al., 2003; Araújo, Sampaio, 2000; Araújo et al., 2004). Desse modo, pesquisas que visam produzir material fúngico de maneira economicamente viável são extremamente necessárias e um passo importante para viabilizar a produção comercial de fungos nematófagos, com melhor custobenefício para o agronegócio. 


\section{REFERÊNCIAS BIBLIOGRÁFICAS}

ALVES, P.H.; ARAÚJO, J.V.; GUIMARÃES, M.P. et al. Aplicação de formulação do fungo predador de nematóides Monacrosporium thaumasium (Drechsler, 1937) no controle de nematóides de bovinos. Arq. Bras. Med. Vet. Zootec., v.55, p.568-573, 2003.

ARAÚJO, J.V.; GOMES, A.P.S.; GUIMARÃES, M.P. Biological control of bovine gastrointestinal nematode parasites in southern Brazil by the nematode trapping fungus Arthrobotrys robusta. Rev. Bras. Parasitol. Vet., v.7, p.117-122, 1998.

ARAÚJO, J.V.; GUIMARÃES, M.P.; CAMPOS, A.K. et al. Control of bovine gastrointestinal nematode parasites using pellets of the nematode-trapping fungus Monacrosporium thaumasium. Ciênc. Rural, v.34, p.457-463, 2004.

ARAÚJO, J.V.; SAMPAIO, W.M. Effects of temperature, mineral salt and passage through gastrointestinal tract of calves on alginate formulation of Arthrobotrys robusta. Rev. Bras. Parasitol. Vet., v.9, p.55-59, 2000.

ARAÚJO, J.V.; SAMPAIO, W.M.; VASCONCELOS, R.S. et al. Effects of different temperatures and mineral salt on pellets of Monacrosporium thaumasium - a nematode-trapping fungus. Vet. Arhiv., v.80, p.181-190, 2000.

ARAÚJO, J.V.; SANTOS, M.A.; FERRAZ, S. et al. Antagonistic effect of predacious Arthrobotrys fungi on infective Haemonchus placei larvae. J. Helmintol., v.67, p.136-138, 1993.

ARAÚJO, J.V.; SANTOS, M.A.; FERRAZ, S. et al. Biological control in vitro of infective Haemonchus placei larvae by predacious fungi Arthrobotrys musiformis. Arq. Bras. Med. Vet. Zootec., v.46, p.194204, 1994.

ARAÚJO, J.V.; SANTOS, M.A.; FERRAZ, S. et al. Controle de larvas infectantes de Haemonchus placei por fungos predadores da espécie Monacrosporium ellypsosporum em condições de laboratório. Arq. Bras. Med. Vet. Zootec., v.44, p.521-526, 1992.

ARAÚJO, J.V.; STEPHANO, M.A.; SAMPAIO, W.M. Passage of nematode-trapping fungi through the gastrointestinal tract of calves. Vet. Arhiv. v.2, p.6978, 1999 .

BARGER, I.A. The role of epidemiological knowledge and grazing management for helminth control in small ruminants. Int. J. Parasitol., v.29, p.41-47, 1999.
BARRON, G.L. The Nematode-destroying fungi: topics in mycobiology. Guelph: Canadian Publications, 1977. n.1, 140p.

DIMANDER, S.O.; HÖGLUND, J.; UGGLA, A. et al. Evaluation of gastro-intestinal nematode parasite control strategies for first-season grazing cattle in Sweden. Vet. Parasitol., v.111, p.192-209, 2003.

DUDDINGTON,C.L. Notes on the technique of handling predaceous fungi. Trans. Br. Mycol. Soc., v.38, p.97-103, 1955.

GOMES, A.P.S. Controle biológico in vivo de nematódeos parasitos gastrintestinais de bovinos pelo fungo Arthrobotrys robusta e atividade in vitro de isolados do fungo Monacrosporium sobre nematódeos. 1998. 81f. Dissertação (Mestrado em Medicina Veterinária) - Departamento de Veterinária, Universidade Federal de Viçosa, Viçosa, MG.

LARSEN, M. Biological control of helminths. Int. J. Parasit., v.29, p.139-146, 1999.

LARSEN, M.; NANSEN, P.; WOLSTRUP, J. et al. Biological control of trichostrongylosis in grazing calves by means of the fungus Duddingtonia flagrans. Vet. Parasitol., v.60, p.321-330, 1995.

MACRAE, J.C. Metabolic consequences of intestinal parasitism. Proc. Nutr. Soc., v.52, p.121-130, 1993.

PERRY, B.D.; RANDOLPH, T.F. Improving the assessment of the economic impact of parasitic diseases and their control in production animals. Vet. Parasitol., v.84, p.145-168, 1999.

PRAMER, D. Nematode-trapping fungi. Science, v.144, p.382-388, 1964.

SANTOS, M.A.; FERRAZ, S.; MUCHOVEJ, J.J. Detection and ecology of nematophagous fungi from Brazilian soils. Nematol. Bras., v.15, p.121-134, 1991.

STROMBERG, B.E. Enviromental factors influencing transmission. Vet. Parasitol., v.72, p.247-264, 1997.

STROMBERG, B.E.; AVERBECK, G.A. The role of parasite epidemiology in the management of grazing cattle. Int. J. Parasitol., v.29, p.33-39, 1999.

WAGHORN, T.S.; LEATHWICK, L.Y.; CHEN, L. et al. Influence of nematophagus fungi, eartworms and dung burial on development of the free-living stages of Ostertagia circumcincta in New Zealand. Vet. Parasitol., v.104, p.119-129, 2002.

WALLER, P.J.; LARSEN, M. The role of nematophagous fungi in the biological control of nematode parasites of livestock. Int. J. Parasitol., v.23, p.539-546, 1993. 